\title{
Correlation of Anteroposterior Diameter of Abdomen with CT Dose Index and Dose Length Product in Abdomen CT Scan- A Retrospective Study
}

RAMESH PARTHASARATHY ${ }^{1}$, ANAND RAJAMANI ${ }^{2}$, EALAI ATHMARAO PARTHASARATHY ${ }^{3}$,

\section{ABSTRACT}

Introduction: Computed Tomography (CT) remains an important tool in diagnostic imaging. Establishment of Diagnostic Reference Levels (DRL) is highly recommended in order to have a check on the radiation exposure.

Aim: To study the correlation between the Anteroposterior (AP) diameter of abdomen with the CT Dose Index (CTDI) and Dose Length Product (DLP) in those who underwent abdomen CT scan.

Materials and Methods: A retrospective study was conducted at Chettinad Academy of Research and Education, in the Department of Radiology during January 2019 to April 2019. The data of 66 patients (44 males and 22 females, aged 18-80 years), who have undergone CT scan during study period of three months were retrieved from $\mathrm{CT}$ console. Axial, coronal, sagittal reconstructions and diameter was measured on axial plane. CTDI and DLP of plane abdomen scan were noted from the dose information from the procedure. CTDI (mGr) and DLP (mGr) were considered as primary outcome variables. Association was assessed by calculating pearson correlation coefficient( $r)$. The $p$-value $<0.05$ was considered statistically significant. Co-guide software was used for data analysis.

Results: There was a moderate positive correlation between AP diameter and CTDI ( $\mathrm{mGr}$ ) (r-value: 0.684, p-value: <0.001). There was a moderate positive correlation between AP diameter and DLP (mGr) ( $r$-value=0.713, p-value <0.001).

Conclusion: The AP diameter of abdomen and CTDI, DLP has positive correlation. Hence, dosage optimisation should be done considering the diameters as indicator.

\section{INTRODUCTION}

Computed Tomography (CT) remains an important tool in diagnostic imaging. Among the diagnostic producers, CT scan is the most significant source of radiation exposure to the patients [1,2]. Establishment of $\mathrm{DRL}$ is highly recommended in order to have a check on the radiation exposure [3]. The DRL is defined as "dose levels in medical radiodiagnostic practices or, in the case of radio-pharmaceuticals, levels of activity, for typical examinations for groups of standard-sized patients or standard phantoms for broadly defined types of equipment, these levels are expected not to be exceeded for standard procedures when good and normal practice regarding diagnostic and technical performance is applied" [3] hence, the body surface area and size of the patient significantly affects the patient dose [4]. Previous available literature has used patient's weight as the main indicator for the size of the patient and these are used as a standardising method $[5,6]$. Gender based differences in the fat distribution also exist, male having fat predominantly distributed in upper parts and females in lower parts of the body $[7,8]$. Fat dispersion in the body can determine the patient dose and the distribution can be inconsistent and may not be useful in calculating $\mathrm{DRL}$. Hence, alternate to weight and fat distribution, usage of body size parameters like AP diameters of the part that is subjected to CT scan can be used as a predictor of CT dose [9,10]. This study was done with objective to study the correlation between the AP diameter of abdomen with the CTDI and DLP in those who underwent abdomen CT scan.

\section{MATERIALS AND METHODS}

A retrospective observational study was conducted at Chettinad Academy of Research and Education, in the Department of Radiology during January 2019 to April 2019. The Institutional Ethical Committee clearance was obtained (235/lHEC/1-19). Waiver of consent was obtained. Data confidentiality was maintained throughout the study. Sample size was calculated assuming the correlation coefficient between AP diameter and CTDI as 0.269 as per the study by Zarb $F$ et al., [3]. The other parameters considered for the sample size calculation included 5\% alpha error and 95\% power of study.

Inclusion criteria: The retrospective data of 66 patients, who have undergone CT scan during the study period were retrieved from the radiology database. Those above 18 years and below 80 years were recruited.

Exclusion criteria: Patients with trauma abdomen and overweight patients were excluded from the study.

\section{Study Procedure}

Philips Brilliance 64 slice Multi-Dimensional Computed Tomography (MDCT) was the machine used for all the patients. The plain abdomen CT scan was performed in standard helical scan according to the protocol. Original data was extracted from CT console to Philips Extended Brilliance Workspace workstation (EBW). The patient was put in supine position, feet first. Domes of diaphragm to Symphysis pubis was the area covered in scan. Cranio caudal direction was done and Postero-anterior (PA) 180 view was done. Slice thickness and increment was kept at $5 \mathrm{~mm}$ each. Standard resolution with standard C filter was used with $120 \mathrm{Kv}$ and $250 \mathrm{mAs} /$ slice. Collimation was at $64^{\star} 0.625$ and 0.984 pitch. Rotation time was $0.75 \mathrm{sec}$ with Field Of View (FOV) $350 \mathrm{~mm}$, matrix 512*512 and 0.0 enhancement. Axial, coronal, sagittal reconstructions were done. Diameter was measured on axial plane from anterior to posterior from the upper pole of right kidney at the level lower border of D12 vertebral body by 
using common tools line. The CTDI and DLP of plain abdomen scan were noted from the dose information from the procedure.

\section{STATISTICAL ANALYSIS}

The CTDI ( $\mathrm{mGr}$ ) and DLP ( $\mathrm{mGr}$ ) were considered as primary outcome variables. AP diameter was considered as primary explanatory variable. Age group and gender was considered as other study relevant variable. Descriptive analysis was carried out by mean and standard deviation for quantitative variables, frequency and proportion for categorical variables. Association between quantitative explanatory and outcome variables was assessed by calculating pearson correlation coefficient( $r$ ) and the data was represented in a scatter diagram. The $\mathrm{p}$-value $<0.05$ was considered statistically significant. Data was analysed by using $R$ (Robert Gentleman and Ross Ihaka) studio and coGuide software, version.1.03 [11].

\section{RESULTS}

Majority of $57.58 \%$ were aged between 31 to 60 years. Among the study population, 44 (66.67\%) were males [Table/Fig-1].

\begin{tabular}{|l|c|}
\hline Parameter & Summary \\
\hline Age group (in years) & $22(33.33 \%)$ \\
\hline $18-30$ & $38(57.58 \%)$ \\
\hline 31 to 60 & $6(9.09 \%)$ \\
\hline $61-80$ & \multicolumn{2}{|c|}{$24(66.67 \%)$} \\
\hline Gender & $22(33.33 \%)$ \\
\hline Male & $27.74 \pm 3.47$ (ranged 17 to 34) \\
\hline Female & $16.93 \pm 4.44$ (ranged 2.14 to 24) \\
\hline CT parameter & $703.26 \pm 286.02$ (ranged 87.60 to 1206) \\
\hline AP diameter (cm) & \\
\hline CT dose index (mGr) & \\
\hline Dose length product (mGr) & \\
\hline [Table/Fig-1]: Summary of demographic parameter (N=66).
\end{tabular}

There was a moderate positive correlation between AP diameter and CTDI (mGr) (r-value: 0.684, p-value: <0.001) and a moderate positive correlation between AP diameter and DLP (mGr) (r-value: 0.713, p-value: <0.001) [Table/Fig-2-4].

\begin{tabular}{l|c|c|}
\hline Parameter & Pearson correlation $(r)$ & p-value \\
\hline CT dose index $(\mathrm{mGr})$ & 0.684 & $<0.001$ \\
\hline Dose length product $(\mathrm{mGr})$ & 0.713 & $<0.001$ \\
\hline \\
[Table/Fig-2]: Correlation between AP diameter $(\mathrm{mm})$ and various score in the \\
study population ( $\mathrm{N}=66)$. \\
Bold values denote significant p-values
\end{tabular}

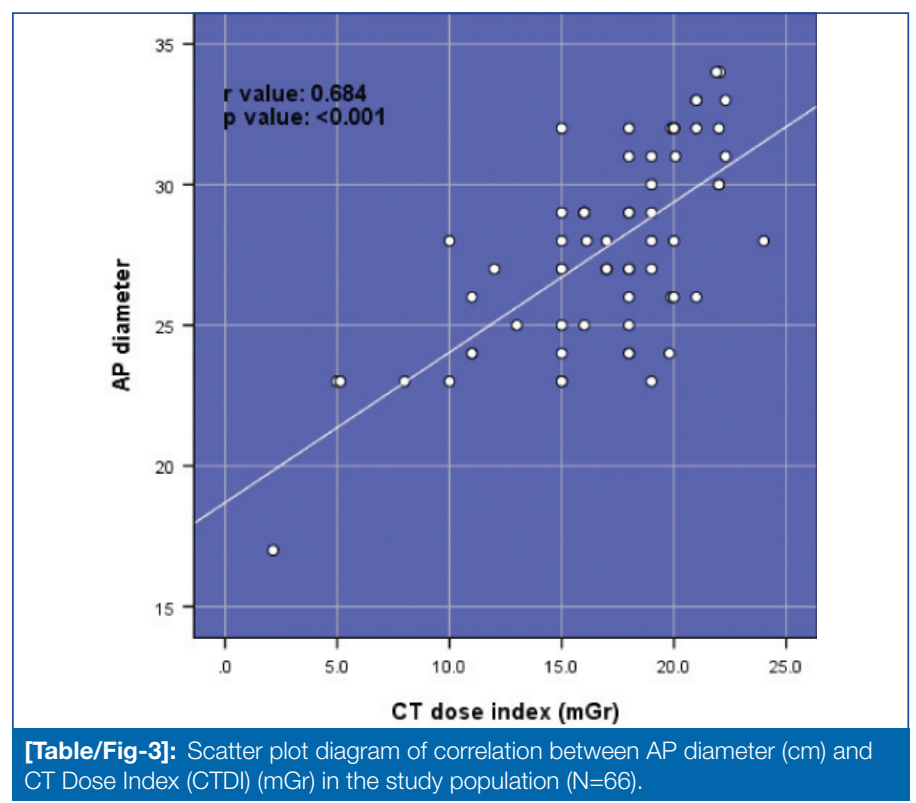

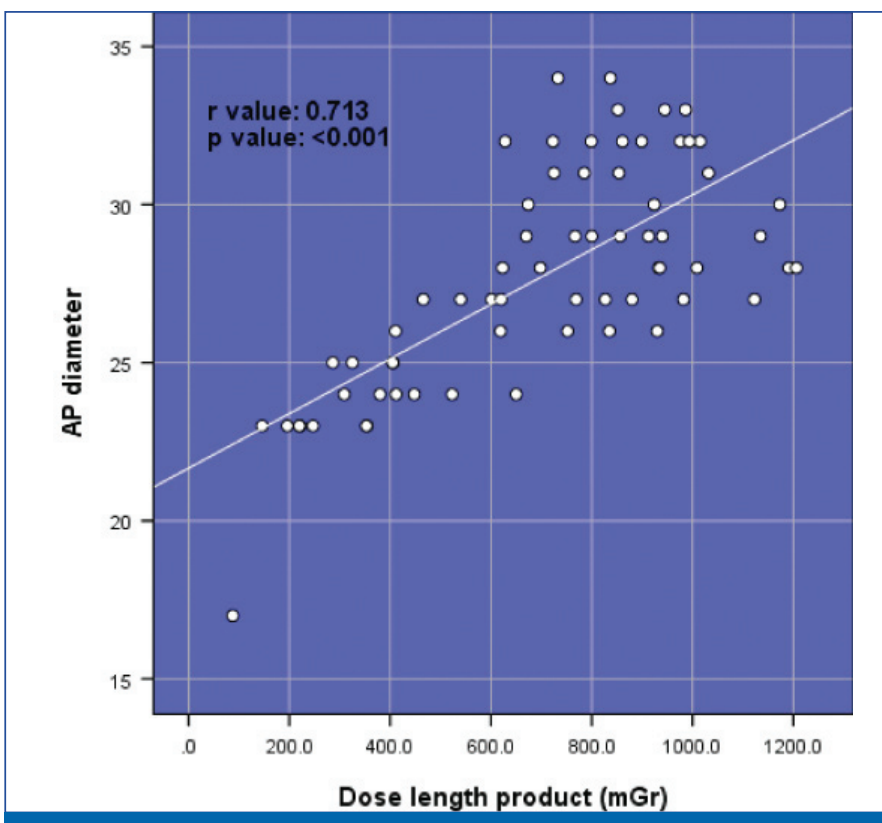

[Table/Fig-4]: Scatter plot diagram of correlation between AP diameter (cm) and dose length product (DLP) ( $\mathrm{mGr}$ ) in the study population ( $\mathrm{N}=66)$.

\section{DISCUSSION}

Based on the present study findings, there is a positive correlation between the anterior and posterior diameter of abdomen with the CTDI and DLP. Previous published literature have accepted the fact that patient dimensions measured through diameters are more significant than weight in deciding the patient dose [12]. Alteration of scanning parameters as per the diameter of the anatomical cross section being scanned can result in significant reduction in radiation exposure. By this technique, thin built patients are exposed to less doses of radiation on the basis of their abdominal diameter [13,14].

Based on the present study findings, there is a positive correlation between the anterior and posterior diameter of abdomen with the CTDI ( $r=0.684)$ and DLP ( $r=0.713)$. This is similar to the findings observed by Bashier EH and Suliman II, where the study population was children and similar positive correlation was established $\left(r^{2}=0.09\right)$ [15]. another study by Zarb $F$ et al., was done to show the advantage of using AP diameter than weight as an indicator of the dosage $\left(r^{2}=0.269\right)$ [3]. The researchers concluded that the AP diameter usage is advantageous that it can be easily measured before scanning or can be calculated based on the previously available images.

Previous published literature for determining CT scan parameters showed that AP body diameter correlated better than weight with image quality and radiation dose [3,9]. The measurements of $\mathrm{AP}$ diameter can be obtained directly from the patient before scanning or during the CT scan when the patient is supine. This measurement can be done by measuring the AP height from the table top, which is in contact with the patient's back, to the top of the patient [3].

\section{Limitation(s)}

The retrospective nature and the limited sample size were the limitation in this study.

\section{CONCLUSION(S)}

The AP diameter of abdomen has a positive corelation with CTDI, DLP. Hence, measurement of diameters before initiating the scan procedure and optimisation of dosage should be followed as a routine at the Radiology Departments. Specific dose optimisation strategy based on the patient diameter can be developed and followed in order to reduce the radiation exposure. Prospective studies, with dose optimisation strategy based on AP diameter are recommended in future. Studies on other part CT scans such as chest and head are also recommended. 


\section{REFERENCES}

[1] Sanchez R, Khong PL, Ringertz H. Radiologic protection in pediatric radiology: ICRP recommendations. Pediatr Radiol. 2013;43(8):920-21.

[2] Reading R. Radiation exposure from CT scans in childhood and subsequent risk of leukaemia and brain tumours: A retrospective cohort study. Child Care Health Dev. 2012;38(6):910-10

[3] Zarb F, Rainford L, McEntee MF. AP diameter shows the strongest correlation with CTDI and DLP in abdominal and chest CT. Radiat Prot Dosimetry [Internet]. 2010;140(3):266-73. Available from: https://academic.oup.com/rpd/article-lookup/ doi/10.1093/rpd/ncq115.

[4] Kotre CJ, Reay J, Chapple CL. The influence of patient size on patient doses in cardiology. Radiat Prot Dosimetry. 2006;117(1-3):222-24

[5] Jurik AG, Jessen KA, Hansen J. Image quality and dose in computed tomography. Eur Radiol. 1997;7(1):77-81.

[6] Ware DE, Huda W, Mergo PJ, Litwiller AL. Radiation effective doses to patients undergoing abdominal CT examinations. Radiology. 1999;210(3):645-50.

[7] López-Alvarenga JC, Montesinos-Cabrera RA, Velázquez-Alva C, GonzálezBarranco J. Short stature is related to high body fat composition despite body mass index in a Mexican population. Arch Med Res. 2003;34(2):137-40.
[8] Brann LS. Classifying preadolescent boys based on their weight status and percent body fat produces different groups. J Am Diet Assoc. 2008;108(6):1018-22.

[9] Menke J. Comparison of different body size parameters for individual dose adaptation in body CT of adults. Radiology. 2005;236(2):565-71

[10] Kalra MK, Maher MM, Toth TL, Hamberg LM, Blake MA, Shepard JA, et al. Strategies for CT Radiation Dose Optimisation. Radiology. 2004;230(3):619-28.

[11] Corp A. coGuide Statistics software. 2020.

[12] Nyman U, Ahl TL, Kristiansson M, Nilsson L, Wettemark S. Patient-circumferenceadapted dose regulation in body computed tomography. A practical and flexible formula. Acta Radiol. 2005;46(4):396-406.

[13] Greess H, Wolf H, Baum U, Lell M, Pirkl M, Kalender W, et al. Dose reduction in computed tomography by attenuation-based on-line modulation of tube current: Evaluation of six anatomical regions. Eur Radiol. 2000;10(2):391-94.

[14] Kalra MK, Rhea JT, Thrall JH. Clinical comparison of standard- dose and $50 \%$ reduced-dose quality. AJR Am J Roentgenol. 2002;179(5):1101-06.

[15] Bashier EH, Suliman II. Radiation dose determination in abdominal ct examinations of children at sudanese hospitals using size-specific dose estimates. Radiat Prot Dosimetry. 2019;183(4):444-49.

\section{PARTICULARS OF CONTRIBUTORS:}

1. Assistant Professor, Department of Radiodiagnosis, Sri Muthukumaran Medical College Hospital and Research Institute, Chennai, Tamil Nadu, India

2. Associate Professor, Department of Radiology and Imaging Sciences, Chettinad Hospital and Research Institute, Kelambakkam, Tamil Nadu, India.

3. Associate Professor, Department of Radiology and Imaging Sciences, Chettinad Hospital and Research Institute, Kelambakkam, Tamil Nadu, India.

4. Professor and Head, Department of Radiology and Imaging Sciences, Chettinad Hospital and Research Institute, Kelambakkam, Tamil Nadu, India.

5. Lecturer, Department of Radiology and Imaging Sciences, AJ Institute of Medical Sciences, Mangalore, Karnataka, India.

NAME, ADDRESS, E-MAIL ID OF THE CORRESPONDING AUTHOR:

Gurubharath llangovan,

$100 \mathrm{~A} / 5,11^{\text {th }}$ Sector, $66^{\text {th }}$ Street, Ponnambalam, Salai KK Nagar,

Chennai-600078, Tamil Nadu, India.

E-mail: kavinilangovan@yahoo.co.in

\section{AUTHOR DECLARATION}

- Financial or Other Competing Interests: None

- Was Ethics Committee Approval obtained for this study? Yes

- Was informed consent obtained from the subjects involved in the study? NA

- For any images presented appropriate consent has been obtained from the subjects. NA
PLAGIARISM CHECKING METHODS: [Jain Het al.]

- Plagiarism X-checker: Mar 22, 2021

- Manual Googling: Jun 21, 2021

- iThenticate Software: Jul 23, 2021 (6\%)
ETYMOLOGY: Author Origin

Date of Peer Review: Jun 05, 2021

Date of Acceptance: Jun 22, 2021

Date of Publishing: Oct 01, 2021 